\title{
Forwarding strategies for online multiple-choice tests
}

\author{
Pramote Danpradit $^{1}$, Tanit Kongkumnerd ${ }^{2}$ \& Pranrapee Boonplian $^{3}$ \\ ${ }^{1}$ Daprtment of Music, Faculty of Music, Bangkokthonburi University, Thailand \\ ${ }^{2}$ Department of Music, Faculty of Music, Bangkokthonburi University, Thailand \\ ${ }^{3}$ Faculty of Humanities and Social Sciences, Nakhon Pathom Rajabhat University, Thailand
}

\begin{abstract}
After the final test of the semester $2 / 2020$ test results of the Aesthetic Appreciation courses (focus music content), learners did not score satisfactorily. The aesthetic Appreciation courses committee analyzed the problem together with the assessment results. This article is a study that compiles knowledge and ideas from academic documents and teaching experience in Aesthetic Appreciation courses, resulting in an article improving teaching using strategies do online multiple-choice tests as follows: 1) Ability to use a computer and typing skills. 2) Ability to read comprehension. 3) Ability to create multiple-choice, 4) Teaching as a tutor role, and 5) The online test, and points to be aware in online testing. In addition, the researcher will continue to apply this concept and create an online test in teaching. There are also ideas for teaching design. This research can be used for guideline in other courses in the future.
\end{abstract}

This is an open access article under the CC BY-SA license.

\section{Corresponding Author:}

Pramote Danpradit

Department of Music

Faculty of Music

Bangkokthonburi University

Thailand

Email: pramote.dan@bkkthon.ac.th

\section{INTRODUCTION}

Clinton \& Hokanson, (2012) present research and theoretical perspectives on creativity and instructional design. It presents a conceptual model of the connection between Clinton's structure, creativity, and design. Design/Creativity Loops (DCL). The center of the model is a representation of an iterative solution cycle. It is the reason why instructional designers often encounter problems with project design. These tasks or delima create repetitive mental excursions, which lead to opportunities for creative thinking. In, addition Yates (2011) presents the research examines the experiences of several beginning teachers who completed their initial teacher education solely in the online mode. The methodological approach was a multiple case study underpinned by a constructivist paradigm. This thesis identified recommendations to improve the online initial teacher education learning experience. Lecturers need to make full use of Web 2.0 tools to develop tasks that create learning communities and dispel the feeling of isolation.

Since the second semester of 2019, with the coronavirus disease pandemic (COVID-19), teachers and students have to search for guidelines for teaching and learning and choose to teach online. Electronically Examination with various programs (Nakhon Pathom Rajabhat University, 2021). The Aesthetic Appreciation courses are compulsory fundamental courses that possess students in different fields at the undergraduate level to focus on enrollment. The content of the courses creates experiences in visual arts, musical art, Thai classical drama, performance art, aesthetic perceptions, and appreciation. The research team, therefore, chooses to develop a test and promote the teaching in the content of music (Aesthetic Appreciation Course, 2021).

The results of the meeting of the Aesthetic Appreciation courses committee at the end of semester 2/2020 were concerned about the low average scores of the tests in each subject matter. Due to the high performance in 
other areas, the average student's assessment results pass the criteria, so the meeting is worried and wants the teacher to focus on enhancing the experience in various fields, further wants the students to test the results. Average higher than last semester (Aesthetic Appreciation committee, 2021). Every meeting we agreed to stay connected to learn through the Zoom application like teaching in a real classroom. The communication through LINE application can organize suitable group and doing exercises, and quizzes through Google forms. This strategy lets the research team to improve and design learning materials to be suitable especially for music samples, audiovisual systems, and all tests. Creating an understanding experience mixed with a question-answer and a discussion of the song samples that were watched each time.

Forwarding strategies to online multiple-choice tests are academic papers that offer guidelines for teaching online and to address learners' reading and interpreting skills. The author, therefore, proposes five strategies: The ability to use a computer and typing skills, the skill of changing the meaning, creating a consistent test, teaching as a tutor role, and technique taking the student's online test. To make teaching more direct and successful, give learners more knowledge and score above median, through the adjustment of both the teacher and the learner. Based on the concept of assessment and investigation of the test. Upon learning of the resolutions of the Aesthetic Appreciation committee, the researcher contacted some of the learners, to have an informal dialogue, and to find out about problems taking the exams of the previous semester. The researcher summarizes the difficulty and solutions for improving teaching and online testing in the next semester, the trials can be done away with after the discussion issues:

1. Ability to use a computer and typing skills.

2. Ability to read comprehension.

3. Ability to create multiple-choice

4. Teaching as a tutor role

5. The online testing, and points to be aware to do online testing

From the earlier issues stated. This article is not intended to create a standardized test or experiment. various platforms. The goal of the presentation is simply to teach learners to be aware of self-examination, and to listen to advice on how to do the test consciously while using their mobile devices for study, entertainment and personal business. Simultaneously not cause any negative effect on any part. The author has tried to revise it for the students to return to develop the comprehensive test again, and will likely present five strategies to further improve teaching.

\section{ABILITY TO USE A COMPUTER AND TYPING SKILLS}

Laborda (2007) presents an academic paper entitled Introducing standardized ESL/EFL exams. This paper will present the features, and a brief comparison, of some of the most well-known high-stakes exams. The greatest challenge is not preparing the test or producing a testing platform that can test faster and more efficiently than teachers do today, but rather, first, being able to develop specific items only designed for computers and, second, studying how the results and correction of online tests can lead to learning (Chapelle \& Douglas, 2006). Using some testing platforms includes comments from the raters but it is not clear whether these comments lead to language learning. From a traditional perspective, computer-based tests are usually composed of multiple-choice questions. Traditionally set as a vertical list of questions with answers, today most exams present only one question at a time. This allows for both a bigger font size for questions and answers as well as larger displays of any media when they occur as prompts for a question.

Additionally, Laborda (2007) has reviewed high stakes tests for the testing platform from several articles, providing examples and guides on how to choose appropriate trials. In the future, most standardized tests will go online or be based on intranet technology. There are some issues with technical access, test items that are not tailored to the computer platform, and the unknown effects of computerized tests on language instruction that need to be addressed. Therefore, this report is a guideline to convey to learners before taking the online test further.

In case of having to take down and organize the test before yourself. The author solved the problem by introducing computers and utilizing Microsoft Word 2016 in the file management content. Speeding up basic computer systems Page setup (Layout-Margins) column arrangement (Layout-Columns) bracket test (Line Number), selection, and format of characters. (Font-spacing) Page Number Format Setting the first page and different pages (Headers and footers). Adding special characters and (Equation) set the printing options. It also introduces related video clips by using keywords such as teaching Microsoft word usage, Microsoft Word shortcut keys, Microsoft Word techniques for doing quizzes, classwork to use time in class, and appointments outside of class.

These skills are Hard Skills or skills used in fundation work that students must study or have previous experience. However, with the code of conduct, instructors have to improve Hard Skills together with Soft Skills go at once In addition, teachers must not forget that many learners use their mobile phones to do online exercises. That is necessary if the learners have to type text, causing delays and wasting time. Therefore, the reading 
perspective the pressing of different answers also the inability to go back and correct the error again. Here puts pressure on mobile or computer users and must have the aptitude to use the device.

\section{ABILITY TO HAVE READING COMPREHENSION}

Reading comprehension or the skill of changing the meaning is a fundamental ability to read, in other words. Acclimated and use summarizing the knowledge and understanding in the content to lead to the creation of questions and options to study and solve reading problems, Judith \& Keith (2008) presentED a comprehensive reading research report on cost or benefit meaning. With enhanced reading comprehension and deep learning, the candidate's help is necessary for developing reading strategies that enhance this process. The coercion of interest does not necessarily increase meaning or well instruction. The reward from simple reading or this essay It's just a study of the theory about deep learning and its impact (Mekrat, 2012). For example, participate in reading and recommend multi-faceted assignments and continue to strengthen reading comprehension for success, in line with Troy et.al. (2019( used text-based reading discussions. The author uses the practice guidelines to accompany clear instructions. Follow a close reading of four steps (discussion norms, principle text accompanying, and discussion) with five primary-level candidates, suitable for use with a small number of learners, per the test-takers in research that only numbered five people and had the poor reading ability. Therefore, the said concept was put in for editing by teaching reading comprehension. With introducing the principles of reading comprehension according to the four processes by the following reading comprehension principles.

1. Read the story on various topics from beginning to end when understanding it once.

2. Readers must always have questions in mind, "What? When? Where? Why? and How?"

3 . Read round 2 with tick or mark. Find such questions or answers.

4. Apply the notes or text on the stroke or use different colors. Marked come to compose to keep the original message or get concise or change some words or have more examples but still have the same meaning.

To check such reading comprehension requires constant reading and writing practice. However, the rationale given by the example may vary in scope and time frame, for that reason an interpretation from the perspective of the reading experience is imperative. The author then describes the content of the critical reading twice and gives a review question for every sample. Simultaneously, the same or similar documents and tests are used as examples. By focusing on building knowledge and understanding of asking questions and making decisions (Clinton \& Hokanson, 2012).

Based on this method, the authors found that test-takers tend to create quizzes that focus on asking questions and answers literal or from memory. By choosing the necessary sentences, specific names, dates, times, and places. I remember carefully the story. Choose to remember numbers, the order of concepts. (Judith et.al., 2008; Mekrat. 2012) As a result, test-takers themselves are unable to answer more complex questions. Another thing is that test takers and respondents often use copying of clue sentences from a book to ask or answer questions without changing the format, confusing the reader with the copied sentences. Therefore, the excerpt is not an understandable question, but the options may be variables that determine the correct clause, however, in the wrong form of the linguistic syntax. Therefore, evaluative reading comprehension and writing well before taking the test will help modelers get more accurate.

Therefore, after the introduction, reading comprehension, and typing/writing. Based on the above problems, the author proposed the development of reading comprehension by creating a test. It is a tool to reinforce, read, comprehend, reflecting or measure the results of questions and quiz choices. The researcher selected the old test, mixed with the newly created test, Sort out accordingly and according to the content that focused mainly on knowledge, and used two groups of students in semester 1/2021 as an experimenter. Finding errors and difficultyeasy values before implementing them for improvement and practical use in semester 2/2021, but only 1 group of teachers used a tutor role style.

\section{ABILTY TO CREATE MULTIPLE-CHOICE TEST}

The ability to create a test means writing questions and options, consisting of questions and choices from which test takers must select the correct option and one accurate or best answer. (Tarrant and Mohammed. 2009; Little, Bjork, E., Bjork, R., and Angello. 2012) Therefore, to focus on explaining and pay attention to reading and writing the Thai language, for developing write questions under the goals. The test covers the content by determining the degree of knowledge and memory understanding, application, and analysis in the cognitive domain. The authors reviewed the documentation for enhancing the ability to create a good test by Siri Peng (2018 (, report at develop a Thai reading and writing test to establish normal and use test manuals in primary students, the quizzes are multiple-choice, matched and subjective, prepaid-answer in two areas: reading test and writing test.

Besides, there is a report by Onnangyai (2012( that proposes a thesis to create an analytical thinking test. According to Marzano's approach (Marzano's taxonomies), five sides were; matching, classification, analysis of errors, summarizing general guidelines, and summarizing specific. This approach is used by the authors to guide 
learners to use in the construction of quizzes, most of the quiz creator's problems involve writing questions and options following the content set. Besides, the choice must also consider the probability of being close to the correct, so that students' answers are difficult to guess. The author also notes that several tests ask questions about number, date, sequence, all of which emphasize memory levels too much. Such is not a test created to promote understanding, application, and analytical thinking. Thus, the question design will become more complex, as Pichitrit (2012) Khunkaew (2019), and Danpradit et.al. (2021) suggested that choosing a question that is more explicit and complex. They have adapted from nouns to verbs to help create different levels of quizzes. Based on the revised concept of Bloom's Taxonomy (Lorin et al: 2013), the author offers example questions at different levels according to the above idea. Where music teachers and or other fields can choose to use, the author leaves " $\mathrm{x}$ " for you to choose to add keywords. Until the question, the sentence is complete and can be used further, as in the example in table 1 .

Table 1 Text to choose from when asking questions according to the cognitive measurement level

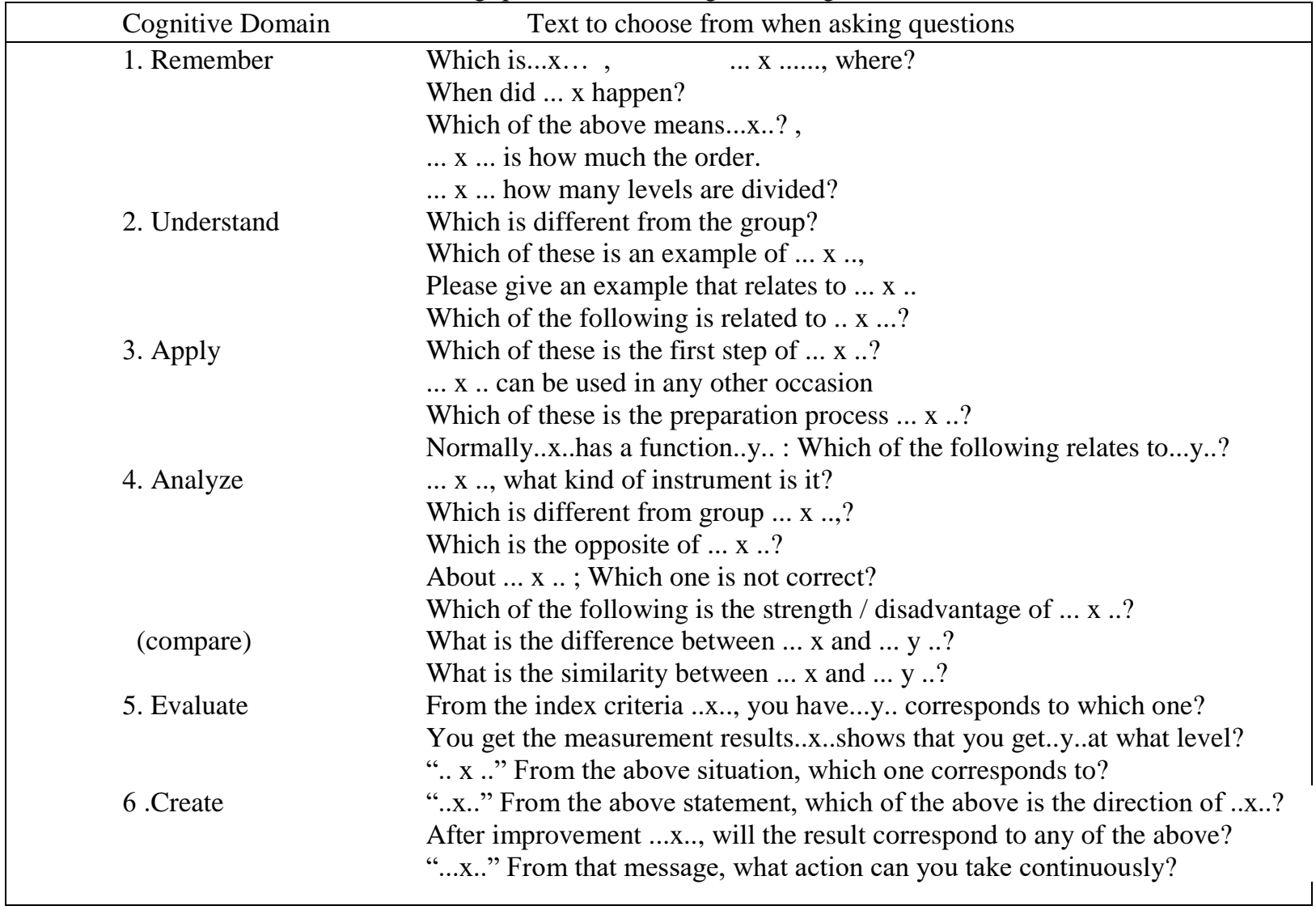

Based on the sample text, test takers can select to design, challenge the test questions to suit their desired behavior level and content. As this is a high-level Thai language strategy, designers tighten their language proficiency due to massive content and quizzes. The authors and learners jointly set goals for the equivalent of each exam and the level framework for creating the test.

\section{TEACHING AS A TUTOR ROLE}

It is an unrecorded teaching used by educational institutions, but it is popular with test-takers at different level out of elementary level to various jobs. Teaching e-tutors for large online classrooms have a role similar to face-to-face tutoring. (Goold et.al., 2010) The problem of differences between generations, that is, Generation X test takers added at the beginning of the tutoring school and improved their academic performance. Slowly when they are parents, they send their children to a particular school. Result in Generation students Y-Z focuses on learning with high scores rather than the performance-related skills (the ability of performance). With the author as a parent, one is concerned and wants to reduce extra learning rather than experience life skills. We, therefore, tried to present the teaching method by analyzing the form of a tutor to show the issue of testing as follows.

1. Search for questions

Searching for questions is a precisely observed for the question you want to ask by reading reviews to find questions, in addition to reviewing the questions, the test taker has to find out absolutely what the questions 
they want to ask. For the reason that the use of language can be a negative question, a sentence overlap, a question overlap question, a negative overlap, a sentence that will confuse the reader.

\section{Find the answer}

Finding the answer had an important issue that test takers have to make the right choice, but which one to choose with a quarter or one-fifth chance of being correct? Sometimes going to an answer may not be necessary, such as 1 in 4 questions. Options will have one different option. Especially for options that were distinctly different, such as ducks, chickens, geese, and dogs, dog choices will be different from most groups. The respondent had to choose immediately by guessing the question if the dog was the wrong answer next choice was unsatisfactorily.

On the other hand, the shrimp, shellfish, crab, and fish options are similar to each other, which can raise questions on a variety of angles, such as:

Which of these is an animal with a shell?

Which of the following are animals with short bones?

Which of these is an aquatic animal? Readers think about what questions should put a question.

However, if you ask which one is different or which one is different? Apply overlapping questions respondents need to analyze their answers in terms of the nature and differences of each option, such as type, benefit, etc., where the choice may be wrong or correct if the question or choice was unclear.

3. Choose the most correct answer.

Getting the accurate answer if you have questions: Which is the right or the most wrong? Here indicates that every option is practically all correct, but one is the most complete. Techniques, frequently the author selects the question with the longest answer first, assuming that the option with the shorter text was likely to be less or less complete. Such may not always be accurate, as long options can be irrelevant options. So, we need to go back and analyze other options again.

Examples of questions to choose the cheapest one:

What is the meaning of Thai music? (The cheapest?) But don't need to enter, you have to choose the cheapest one)

a. Learners' brain ability to remember. evaluation, appreciate sound

$b$. Learners' brain ability to remember. evaluation, analysis, sound experience.

$c$. The ability to bring knowledge understanding can be listened to, arrange the sounds to be beautiful.

From option, item $c$. has the longest message. If you use guessing, there will be left $b$. and $c$. Part $a$. repeat before the text with $b$. Therefore, the $a$. is eliminated. The respondents have $c .50 \%$ more chance of being right.

4. Selection of Situation Analysis and Conditional Response.

4.1 Selection of situational analysis answers.

So far analytical answers or situation or chronological questions. In general, which principle or theory will it relate to? The stories raised are often directly or complex in hypothesis. There may be questions that follow. From the above situation, how will the problem be solved? Therefore, at this point, the test taker has to memorize or understand the principles and theories. Or give more complex examples of assumptions.

Creating and choosing scenario-type responses is complex, for example:

"What is the name of a stylized instrument? : a. Jakea, b. Jorakea c. Krajab d. Pi"

From the example of the above questions, what is the exam grouped under the concept of music?

$a$. strum/pluck $\quad b$. stringed instruments $\quad c$. Classification of musical instruments by behavior

This question first, the respondent must know what the $b$. Jorakea means amphibian or crocodile (in Thai). c. Krajab means one plant, the root part is boiled as food. $a$. Jakea and $d . P i$ is the names of Thai musical instruments. Question 2, What is the meaning of the instrument group, according to the answer in c., but the question may confuse the reader. Therefore, the respondent should read the choice to make a decision. The principle used to make this decision is the principle of classifying musical instruments according to playing behavior (Thai style).

4.2. Conditional selection of answers

Choosing a conditional answer must be consistent with the question. The respondent must analyze the question and answer in detail and be competent to identify the procedure in which such conditions are consistent with that question. In this regard, students must use the comprehensive resolution and review every option to see if it is coherent or relevant. By educator's suggestion eliminating irrelevant options first if they are pertinent or similar, then all options must be checked to see if they comply with the conditions instead.

Examples of conditional questions.

Question: There are several levels of listening, which should a student have a level of listening ability comparable to? 

a. Guest
b. Musician-Artist
c. Instructor-Music Critic
d. Composer-Arranger

Respondents, must first understand the level of listening ability that requires entertainment or content, then bring yourself to compare, but don't forget that, the question asked about general students is not specific to music students or music teachers.

Question: Why is "using too much pressure on both the string and the fiddle bow, resulting in unsatisfactory fiddle sound?" from the message which corresponds to.

a. Understanding the playing skills

b. Sound production

c. sound source

From the example, good vocal production is an early skill of playing stringed instruments. Respondents, must know the bow and practice in order to produce quality sound.

Putting down conditions can be more complicated to ask, for example:

Question: The 1st guitar is the string with the highest pitch: If I want a lower pitch (normal guitar), which one should I choose?

a. Pick line 6

b. Pick a call that is low tone.

c. Change the 6th line to a larger one.

d. Press the string at the low noise position.

In terms of the conditional questions refering to the highs, the question asks about the intonation, indicating that it is not a normal or normal guitar. So, the options can be more complex and conditional, the reader has to debate, find and make the correct choice.

Therefore, both situation and conditional questions, are behavioral questions at the analytical and valuation level. With a point of observation that there must be 2 or more variables and that is the cause of the continuous hair Because of the condition, it cannot be done for the reason of one thing. For tutoring as a tutor, it does often recommend skipping this as it will waste time on the simpler ones. If you have time then come back and do it again.

Such tutoring may be a tactic of doing quizzes or teaching "Guess teaching", which introduces a method for choosing correct guesses, using guesswork. Without a basic understanding of the subject, only 5-10 percent of the test may be performed. With prior knowledge or practice, there was a higher chance of doing it right. After the author has recommended the test. I have chosen to review and re-evaluate the test. Even with higher scores, on median fifty percent of the number of people taking the exam. The author inquired and found additional problems about the online test system, which made the test taker nervous because each time the test was different. The system will toggle both the sequence of questions and alternate options, further significantly, the opportunity to go back and revise the previous one, or the time is not enough, so the online exam has other factors that unchecked. However, I was aware of the output here, referring to the outcome of the test, measurement, and evaluation of each group of students.

This is a teaching that integrates project-based research. The instructor acts as a coach to assist in reporting rather than as an instructor in the original sense, therefore introducing, offering examples, sharing, analyzing, solving problems does part of the process that the trainer provides. Successful support does no different from Nguyen (2020) reports using STEM-based teaching, solving learning problems by having students design a bamboo toothpick house. The author uses the report on the findings of the test, measurement, and evaluation. Causing students to study the principles thinking of solving problems Practice reviewing the use of Thai language until you can finally create and take the online test. Therefore, doing the test will establish knowledge that the learner has accumulated. Take it out for analysis and answer the questions. Teaching as a tutor must point out both knowledge and use in analysis in which the example using the original test or the test with the same content as the subject taught is an issue that tutors need to search from the old sample or create a new one to be a teaching example. enabling learners to have both strategies and content concurrently

\section{THE ONLINE TESTING AND POINTS TO BE AWARE}

Online exams have come with online teaching management (Carol, 2020), but in this case, this is typical teaching only delivered through ASC (https://assess.com/online-testing) Classmarker, (https://www.classmarker.com), Quizizz (https://quizizz.com), Tencent (https://wj.qq.com(, Zoom application, and Google forms etc, so it's a semi-online teaching system. The online test is a new method for Thai teachers and students, from previous experience there was only some agency online questionnaires (Anderson \& Gerbing, 1991; Danpradit et.al., 2021) Therefore, the authors review the reports. Found problems and consistent guidelines by introducing them to learners before taking the test. In 
addition, the author exchanged inquires from the examining teacher-related person. It is put in place that there were some systematic problems in the systematic test and the feeling was not exceptionally different in the areas of panic.

1. Excitement, anxiety, time, and the online system of examining candidates reflected much of their anxiety. With the problem of increasing the number of remaining times at that time, even though the time was remaining more than usual. This does a system of each program that is used. Continuing with the problem of needing to revisit, but with the online system in a forward-thinking manner, it may not be designed to be able to go back and view past quizzes or to revise it again, making the timeline Doing most of the rest of the test.

2. To take the test, it was necessary to have a short trial period, to build familiarity with the system and check if the email is correct or not, because the test taker found that the password was remembered. You cannot receive your email address, so you need to change your email address. If the author specifies the name and password there are other problems, but it is just a problem for the teenagers.

3. The number and duration of the test, based on a lot of content and no experience in doing the test. As a result, the number of tests that were created resulted in a large amount of time. The researcher asked the test takers to agree that, the duration should not exceed 60 minutes of each set. But there are fewer tests Even more attracted to the exam.

4. Do not take the online test for repeating the test. To study or assess various, because test takers can record their screens, making the test a secret to the next exam.

Examples of programs or websites to create online exams: In this article, we offer 2 programs, Hmmquiz and Google forms.

\section{Program Hmmquiz}

The author chose to use the Hmmquiz program because it does not block from some countries and, more importantly, it was a convenient program to use, able to choose from many types of exam types, including multiplechoice, filling in matching words, can add, reduce, edit questions and words. Reply to insert a still image, a movie can increase the weight of the test individually. Also, the difficulty of the test can be calculated.

Access for exam takers Hmmquiz website (https://app.hmmquiz.com). Administrators were required to set the class and add the name of each class member in the Classes menu according to the quiz taker menu. Users can do 2 types. The exam schedule arrives, the system will send it to the person's email address. The test taker will use each person's email and password to enter the system and 2) use their ID and last name. The system will set a new name and password. Administrators must submit a username and password for specific people. Method 2, the system assigns a name and password to Will be difficult for people to distribute to each candidate. The method of using the test taker's E-mail will be typed in error copying and remembering the password of the candidates themselves. There may be times when the test taker's e-mail cannot be used with the system.

\section{Program Google-forms}

Google forms is owned in Google Drive (Google workspace) where educators can design multiple-choice questions, fill in words, and more just like any other online quiz program but it's free. The creator simply sends the address link to the test-takers, then the test taker can take the test and complete the test. You can switch questions, switch answers, and send the results of the exam as you like. It can also show the average and wrong answers to the creators. Therefore, in this research, being a Thai student, the researcher chose Google forms to develop the exam.

One thing to be aware of, the use of different programs is that the program that will be used in the test should be introduced to the learner in advance, especially the menu of each program may create a misunderstanding during the exam, therefore An acquaintance guide, along with a lab test may be necessary for the first trial.

Note: Points to be aware to do online testing

1. Convenience, speed, cost savings in paper usage, examination, and achievement assessment facility.

2. Reduce the problem of peeling tests or not being able to peel each other due to the exam system using random questions and answers during the exam time, making each test inconsistent. Incidentally, with a limited time, the test takers do not have much time to inquire as everyone is doing the test at the same time.

3. Online exam, attracting more people to take the exam Take a lot of tests. But the number of exams should not be more than 30 per set or 30 questions each time, because going to do it for a long time may have problems with the speed of the Internet.

Therefore, after teaching as a tutor, using test development as a teaching management tool. Benefits that occur to the candidates. Get both pieces of knowledge in the content that created the quiz obtain methods for checking the validity, consistency of content, and level of measurement behavior. Which the author has explained with the main content from the book document with the knowledge of the principles before. But after assessment by creating a preliminary test. Therefore found a very low evaluation. The test taker did not care that the test he had created would return to be tested for himself, but when the author revisited it. Has raised awareness of learners and has better overall assessment results in which the destination of the measure of learning achievement is the measure of knowledge the ability of the learners according to most of the learning topics that was a measure of the brain or cognitive domain. It is all a process of enhancing the experience of developing a test that is a skill that does take by the students. 
So in the next research process, the author will use it to create a test to trial, the tests of each group were examined and tested. To find the difficulty of wrong words, right, and so on with people taking the examination, a total of 24 participants were tested during September-October 2021 through the online system with a test program (try out) to check the structure and displayed messages. The author using the program Google-forms able to pass all tests of $61 \%$ of all tests and found that the number of difficult tests reached $14 \%$.

For music content, Instructors choose to use the Zoom or the Voov meeting program for lectures, appreciation of sample songs, Line groups, and quizzes through the Google forms program. The teaching was conducted 5 times ( 3 hours/time) and the scores were collected 5 times according to the content area that emphasized enhancing the experience of Thai and Western music, especially the enhancement of taste through listening. The created test section focuses on measuring memory and comprehension, categorizing different content types. In which the teacher and research team choose from the tests that have been used in the past semester. The researcher designed and selected a test that was related to the old questions. or adjust a new question and volunteers to test the system in the amount of $15 \times 5=75$ items (Table 2).

Table 2 Number of quizzes with defined weight values, behavior levels and chapter content

\begin{tabular}{|c|c|c|c|c|c|}
\hline \multirow{2}{*}{ The content of test design } & \multicolumn{4}{|c|}{$\begin{array}{l}\text { Number of tests with weight value } \\
\text { Behavior level Bloom's Taxonomy }\end{array}$} & \multirow[t]{2}{*}{$\begin{array}{l}\text { Number } \\
\text { of tests }\end{array}$} \\
\hline & knowledge & understand & apply & analyse & \\
\hline 1. Musical elements western style music & 5 & 4 & 4 & 2 & 15 \\
\hline 2. Types of musical instruments and Thai bands & 5 & 4 & 4 & 2 & 15 \\
\hline 3. Thai music style & 5 & 4 & 4 & 2 & 15 \\
\hline 4. Western musical instruments and bands & 5 & 4 & 4 & 2 & 15 \\
\hline 5. Western music style & 5 & 4 & 4 & 2 & 15 \\
\hline Total & & & & & 75 \\
\hline
\end{tabular}

Table 2, the assignment of weight, number of exams in each chapter, and behavioral level according to the concept of Bloom's Taxonomy (Lorin, et al. 2013). The author is required to create only four quizzes. The Behavior Level, for Reason, is to create multiple-choice tests, assigning learners to perform as a group, to create 75 quizzes. This was to reserve the right to select the appropriate test for testing, by faculty or experts to reexamine. This table had been used to examine checking the validity of content that may be used continuously to allow experts to examine content validity and criticize the level of behavior in the creation. (Danpradit, Suttamart and Boonplian. 2021) All 5 lessons, which is based on writing questions and options for validation, test quality, as well as selecting the appropriate exam content and behavior to measure results. The researcher chose Google forms to exam.

Future research can explore how these areas interact with each other and how the movement between layers is further verified. However, the relegation of music learning to a model can be both helpful and restrictive. It is hoped that the "envelope" of creativity as previously described by Clinton \& Hokanson (2012) welcomes the freedom to flow between the layers such that authentic musical learning is achieved.

\section{CONCLUSION}

From what the author has stated, this paper is only to offer a solution to the problem of doing online testing. with five strategies: 1) Ability to use a computer and typing skills, 2) Ability to read comprehension, 3) Ability to create multiple-choice/quizzes, 4) Teaching as a tutor role, and 5) The online test, and points to be aware to do online testing. Teachers and students have to adapt to find problems and solutions in online testing, just like doing exercises and Take the test online only. However, the authors will use this approach to enhance teaching in order to increase scores in online assessments in the Aesthetic Appreciation courses and other courses. The model proposed in this paper considers key elements focus on reading comprehension and practice while taking the online test. This may be used as a teaching guide at the high school level, to emphasize music performance continues to grow, the understanding of the intricacies of music performance interactions within an online educational environment. The complexities of combining the teaching of artistic skills and freedom of artistry within an online structure can be overwhelming for future music experts should some type of pathway not be hewn for informed guidance. It is understood that this model. (Clinton and Hokanson, 2012)

\section{REFERENCES}

Aesthetic Appreciation Course. (2021). Course Management 2500116 Aesthetic Appreciation for 1/2021(TQF.3). Faculty of Humanities and Social Sciences, Nakhon Pathom Rajabhat University.

Aesthetic Appreciation Committee. (2021). Minutes of the meeting prepared (TQF.5) for the course on Aesthetic Appreciation. Faculty of Humanities and Social Sciences, Nakhon Pathom Rajabhat University. 
Anderson, J. C., \& Gerbing, D. W. (1991). Predicting the performance of measures in a confirmatory factor analysis with a pretest assessment of their substantive validities. Journal of Applied Psychology, 76(5), 732-740.

Chapelle, C. A., \& Douglas, D. (2006). Assessing language through computer technology. Ernst Klett Sprachen.

Clinton, G., \& Hokanson, B. (2012). Creativity in the training and practice of instructional designers: The design/creativity loops model. Educational Technology Research and Development, 60(1), 111-130.

Danpradit, P., Suttamart, A., \& Boonplian, P. (2021). The multiple-choice exams courses for educational measurement and evaluation. Journal of Education Mahasarakham University, 15(1), 84-101.

Everly, M. C. (2013). Are students' impressions of improved learning through active learning methods reflected by improved test scores?. Nurse Education Today, 33(2), 148-151.

García J. Laborda, (2007). Introducing standardized ESL/EFL exams. Language Learning \& Technology, $11(2), 3-9$.

Goold, A., Coldwell, J., \& Craig, A. (2010). An examination of the role of the e-tutor. Australasian Journal of Educational Technology, 26(5), 704-716.

Gutl, C., Lankmayr, K., Weinhofer, J., \& Hofler, M. (2011). Enhanced automatic question creator--EAQC: Concept, development and evaluation of an automatic test item creation tool to foster modern eeducation. Electronic Journal of e-Learning, 9(1), 23-38.

Johnson, C. (2020). A conceptual model for teaching music online. International Journal on Innovations in Online Education, 4(2), 1-23.

Khunkaew, A. (2019). Evaluation and Evaluation of the New Study. 2nd ed. Chulalongkorn University Press.

Li, F. Y., Hwang, G. J., Chen, P. Y., \& Lin, Y. J. (2021). Effects of a concept mapping-based two-tier test strategy on students' digital game-based learning performances and behavioral patterns. Computers \& Education, 173, 104293.

Little, J. L., Bjork, E. L., Bjork, R. A., \& Angello, G. (2012). Multiple-choice tests exonerated, at least of some charges: Fostering test-induced learning and avoiding test-induced forgetting. Psychological Science, 23(11), 1337-1344.

Mekrat, S. (2012). Unit 7 reading in Gel 1001 Using Thai language. Office of General Education and Electronic Learning Innovation: Suan Sunandha Rajabhat University.

Nakhon Pathom Rajabhat University. (2021). Announcement: Schedule and teaching management model for the first semester of the academic year 2020. Retrieved from https://news.npru.ac.th/u_news/ detail.php?news_id=21004\&ref_id=PR

Nguyen, N. (2020). Using the problem-based learning in STEM teaching about bamboo toothpick houses. International Education Studies, 13(12). 70-89.

Onnangyai, P. (2012). The construction of an analytical thinking ability test for exam takers Grade 6, Office of Education Bangkok. Bangkok: Srinakharinwirot University.

Pichitrit, J. (2012). Principles of measurement and evaluation of studies. 7th ed. House of Kermist Co., Ltd.

Roberts, J. C., \& Roberts, K. A. (2008). Deep reading, cost/benefit, and the construction of meaning: Enhancing reading comprehension and deep learning in sociology courses. Teaching Sociology (TS), 36(2), 125-140.

Siri Peng, B. (2018). Development of Thai reading and writing ability test to analyse learning disabilities for the person who takes the exam Elementary level affiliated with the office Phrae Primary Educational Service Area 2. Phrae Primary Educational Service Area 2: Phrae.

Tarrant, M., Ware, J., \& Mohammed, A. M. (2009). An assessment of functioning and non-functioning distractors in multiple-choice questions: a descriptive analysis. BMC medical education, 9(1), 1-8.

Yates, A. (2011). Something old, something new: initial teacher education in the online mode. Retrieved from https://www.researchgate.net/profile/Anne-Yates/publication/50874959_Something_Old_Something_ New_Initial_Teacher_Education_in_the_Online_Mode/links/54dd78dc0cf28a3d93f94fbd/SomethingOld-Something-New-Initial-Teacher-Education-in-the-Online-Mode.pdf 